\title{
Correction to: Ball milling as an important pretreatment technique in lignocellulose biorefineries: a review
}

\author{
Yalew Woldeamanuel Sitotaw ${ }^{1,2} \cdot$ Nigus G. Habtu $^{1} \cdot$ Abaynesh Yihdego Gebreyohannes $^{3} \cdot$ Suzana P. Nunes $^{3}$. \\ Tom Van Gerven ${ }^{2}$
}

(c) Springer-Verlag GmbH Germany, part of Springer Nature 2021

\section{Correction to: Biomass Conversion and Biorefinery https://doi.org/10.1007/s13399-021-01800-7}

In this article, reference 113 was incorrect and should have been Kępa K, Chaléat CM, Amiralian N, Batchelor W, Grøndahl L, Martin DJ (2019) Evaluation of properties and specific energy consumption of spinifex-derived lignocellulose fibers produced using different mechanical processes. Cellulose 26: 6555-6569.

The original article has been corrected.

Publisher's note Springer Nature remains neutral with regard to jurisdictional claims in published maps and institutional affiliations.

The original article can be found online at https://doi.org/10.1007/ s13399-021-01800-7.

Tom Van Gerven

tom.vangerven@kuleuven.be

1 Faculty of Chemical and Food Engineering, Department of Chemical Engineering, Bahir Dar University, Bahir Dar, Ethiopia

2 Department of Chemical Engineering, KU Leuven, Celestijnenlaan 200F, B-3001 Leuven, Belgium

3 Biological and Environmental Science and Engineering Division, Advanced Membranes and Porous Materials Center, King Abdullah University of Science and Technology, Thuwal 23955-6900, Saudi Arabia 